\section{Questión}

Periodismo / Comunicación ISSN 1669-6581
- Av. $44 \mathrm{~N}^{\circ} 676,1^{\circ}$ piso

CP 1900 - La Plata - Argentina

( www.perio.unlp.edu.ar/question

Hay un litigio entre los medios de comunicación que mienten y los que proponen información de calidad Víctor Hugo Morales - Carlos Milito

https://doi.org/10.24215/16696581e350

\title{
Hay un litigio entre los medios de comunicación que mienten y los que proponen información de calidad
}

Entrevista sonora a Víctor Hugo Morales, conductor del programa "La Mañana" AM750 y autor de la columna política en "El Diario" en el Canal de noticias C5N por Carlos Milito

\section{Resumen}

Las rutinas de producción, la agenda y el tratamiento informativo en tiempos del COVID-19.

\section{Summary}

The production routines, agenda and informational treatment in times of COVID-19..

\section{Palabras Claves}

Radio - Noticias - Agenda - Periodismo - Rutinas de Producción - Derecho a la información Medios hegemónicos - Verdad - Litigio

\section{Keywords}

Radio - News - Agenda - Journalism - Production Routines - Right to Information Hegemonic Media - Truth - Litigation

\section{Víctor Hugo Morales}

Twitter: @VHMok

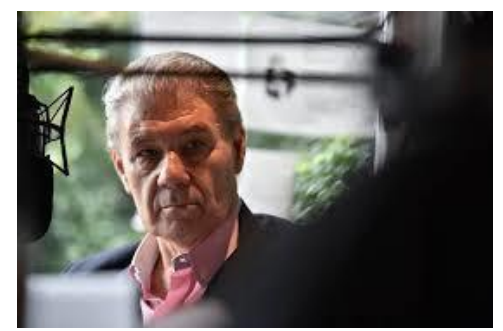


Comunicador, periodista, escritor. Actualmente conduce el programa radial La Mañana, por AM 750 y produce y realiza una columna diaria en el Canal de cable C5N. Es el referente del Equipo Relatores, que transmiten partidos de fútbol por la aplicación del mismo nombre y por AM 530 Somos Radio.

\section{Entrevista}

Carlos Milito.

https://orcid.org/0000-0002-5874-6951 cmilito@perio.unlp.edu.ar

Magister en Comunicación y gestión de procesos comunicacionales FPyCS UNLP Profesor Titular del Taller de producción de contenidos y narrativas sonoras y radiales Director de la Especialización en Comunicación radiofónica - FPyCS UNLP Coordinador de 1894radioonline de Villa Elisa, Provincia de Buenos Aires Locutor comercial de Relatores. Transmisiones Deportivas por la app y AM530 Somos Radio Integrante del IICom (Instituto de Investigaciones en Comunicación) FPCS UNLP

\section{Enlace}

https://ar.ivoox.com/es/51717288 